Print ISSN: 2288-4637 / Online ISSN 2288-4645

doi:10.13106/jafeb.2020.vol7.no9.063

\title{
Foreign Investors' Abnormal Trading Behavior in the Time of COVID-19*
}

\author{
Anya KHANTHAVIT ${ }^{1}$
}

Received: June 02, 2020 Revised: July 19, 2020 Accepted: August 10, 2020

\begin{abstract}
This study investigates the behavior of foreign investors in the Stock Exchange of Thailand (SET) in the time of coronavirus disease 2019 (COVID-19) as to whether trading is abnormal, what strategy is followed, whether herd behavior is present, and whether the actions destabilize the market. Foreign investors' trading behavior is measured by net buying volume divided by market capitalization, whereas the stock market behavior is measured by logged return on the SET index portfolio. The data are daily from Tuesday, August 28, 2018, to Monday, May 18, 2020. The study extends the conditional-regression model in an event-study framework and extracts the unobserved abnormal trading behavior using the Kalman filtering technique. It then applies vector autoregressions and impulse responses to test for the investors' chosen strategy, herd behavior, and market destabilization. The results show that foreign investors' abnormal trading volume is negative and significant. An analysis of the abnormal trading volume with stock returns reveals that foreign investors are not positive-feedback investors, but rather, they self-herd. Although foreign investors' abnormal trading does not destabilize the market, it induces stock-return volatility of a similar size to normal trade. The methodology is new; the findings are useful for researchers, local authorities, and investors.
\end{abstract}

Keywords: Event Study, Herd Behavior, Infectious Disease, Market Destabilization, Trading Behavior

JEL Classification Code: G01, G12, G14

\section{Introduction}

Foreign investors are important for local markets. These investors help to raise trading liquidity and securities supply, bring valuable information to markets, and improve speed of price discovery (Errunza, 2001). However, foreign investors are risk-sensitive and diversify investments in various national markets for risk reduction (Civilize, Wongchoti, \& Young, 2015). Local authorities are concerned about trading

\section{*Acknowledgements:}

This author thanks the Faculty of Commerce and Accountancy, Thammasat University, for the research grant, the Stock Exchange of Thailand for trading volume and stock-index data, and Chanya Siriarayaphan for research assistance.

${ }^{1}$ First Author and Corresponding Author. Distinguished Professor of Finance and Banking, Faculty of Commerce and Accountancy, Thammasat University, Thailand [Postal Address: No. 2 Phra Chan Road, Phra Nakhon, Bangkok, 10200, Thailand] Email: akhantha@tu.ac.th

(c) Copyright: The Author(s)

This is an Open Access article distributed under the terms of the Creative Commons Attribution Non-Commercial License (https://creativecommons.org/licenses/by-nc/4.0/) which permits unrestricted non-commercial use, distribution, and reproduction in any medium, provided the original work is properly cited. behaviors and closely monitor investors (Yaha, Singh, \& Rabanal, 2017), as leading economists, such as Stiglitz (1998), have acknowledged market-destabilizing potentials of these investors. It is possible that foreign investors are panicked due to national or global events, positive-feedback strategies, or herd behaviors, and they move money to invest in other markets (Choe, Kho, \& Stulz, 1999). Although researchers have reported that foreign investors are positivefeedback traders and show herd behavior at times, these behaviors do not necessarily lead to market destabilization (Hood, Kamesaka, Nofsinger, \& Tamura, 2013).

This study investigates the behavior of foreign investors in the Stock Exchange of Thailand (SET) during the period of coronavirus disease 2019 (COVID-19) as to question (1) whether trading is abnormal, (2) what strategy is followed, (3) whether herd behavior is present, and (4) whether the actions destabilize the market.

COVID-19 is an infectious respiratory disease caused by severe acute respiratory syndrome coronavirus 2 . The World Health Organization (WHO) declared COVID-19 a global pandemic on March 11, 2020. Since it was first detected in Wuhan, China, on November 17, 2019, the disease has spread to 213 countries and territories. As of May 23, 
2020, there were 5,318,050 infections and 340,230 deaths (Worldometers, 2020).

From an economic perspective, McKibbin and Fernando (2020) estimated that in 2020, GDP losses from the baselines could be as high as $6.2 \%$ for China and $8.4 \%$ for the United States in certain scenarios. For the rest of the world, GDP losses could be up to $5.9 \%$. Researchers reported that foreign investors reacted negatively to COVID-19. Mehta and Jha (2020) found for India that foreign investors continuously withdraw money from the market, whereas Takahashi and Yamada (2020) found for Japan that stocks with high foreign ownership reacted more negatively to COVID-19 than stocks with low foreign ownership.

This study chooses SET as the sample market because Thailand is one of the world's leading emerging markets. In December 2019, the market capitalization of SET was USD 569 billion. According to the World Federation of Exchanges (2019), SET ranked $11^{\text {th }}$ among markets in the Asia-Pacific region and was the $25^{\text {th }}$ largest market in the world. Despite this market size, foreign investors are relatively large and influential (Richards, 2005). The market has a 30\% share of foreign ownership, and the trading volume of foreign investors has risen steadily. In 2019, the average share was the highest at $41.35 \%$, while shares of local-individual and local-institutional investors were $33.22 \%$ and $11.57 \%$, respectively.

SET was one of the markets in Asia that suffered the largest price drops and worst foreign investor liquidation (Polkuamdee, Chudasri, \& Sangwongwanich, 2020; Bangkok Post, 2020). The link between the market and COVID-19 is interesting. Thailand is the first country outside China that experienced COVID-19 infection. For foreign investors in SET, COVID-19 was, first, a local and regional event, which later evolved into a global event.

During events such as the 1997 Asian financial crisis and the 2011 earthquake in Japan, it is likely that foreign investors behave different than normal. However, researchers (e.g., Karolyi, 2002; Hood et al., 2013) have considered only aggregate behavior, not the differences in behavior. Researchers must deconstruct behavior into normal and abnormal components and consider only abnormal behavior (Lin, Lee, \& Chiu, 2010). Aggregate behavior leads to incorrect conclusions and inappropriate implications if normal behavior is the key driver of results.

This study proposes a significant improvement in research methodology. It analyzes foreign investors' trading behavior using the event-study method, because its main interest is the behavior in the event period. It determines that the difference between the realized aggregate trading volume and its expected level is the sum of the abnormal trading volume due to COVID-19 and the error term. The error term would be present in a normal period. Therefore, this study applies the Kalman filtering technique to extract the abnormal trading volume from the difference and uses the extract to address the four research questions.

\section{Literature Review}

\subsection{Trading Strategies, Herd Behavior, and Market Destabilization}

Foreign investors have often been blamed for destabilizing national markets (Karolyi, 2002). Brennan and Cao (1997) reported a positive correlation of foreign portfolio investment flows and stock returns; the positive correlation is consistent with a positive-feedback strategy followed by foreign investors. Trading as a group, foreign investors create disarray and possible panic in the market. If foreign investors adopt a positive-feedback strategy and trade in herd, their trades can destabilize the market (Choe et al., 1999). However, De Long, Shleifer, Summers, and Walkmann (1990) argued that positive feedback and herd behavior did not necessarily lead to market destabilization. The trades may result from new information; stock price changes are permanent.

Positive-feedback trading among foreign investors has been found in various national markets (Choe et al, 1999; Froot, O'Connell, \& Seasholes, 2001; Karolyi, 2002; Hood et al., 2013). Recently, however, Onishchenkoa and Ulkub (2019) reported for the Korean market that foreign investors gradually shifted from positive- to negative-feedback trading.

Herd behavior is found for foreign investors in national markets such as the Japanese market by Karolyi (2002), the Korean market by Choe et al. (1999) and Jeon and Moffett (2010), and the Taiwanese market by Lu, Fang, and Nieh (2012). Despite the fact that foreign investors are positivefeedback investors, who trade in herd, Choe at al. (1999), Karolyi (2002), Hood et al. (2013), and Onishchenkoa and Ulkub (2019) did not find any evidence to suggest market destabilization.

\subsection{Foreign Investors' Behavior in the Time of Crises}

Crises cause fears and shocks to national and world markets; foreign investors are sensitive to them (Civilize et al., 2015). Significant reactions to crises of foreign investors are found for financial crises (Karolyi, 2002; Bertaut, \& Laurie, 2009), natural disasters (Hood et al., 2013; Anuchitworawong \& Thampanishvong, 2015), and pandemics (Lee \& McKibbin, 2004; Wang \& Thi, 2006).

COVID-19 is the world's most recent pandemic, which has induced economic and financial crises globally. There is evidence to suggest that foreign investors reacted 
significantly to the disease. For the Indian market, Mehta and Jha (2020) found that foreign investors continuously withdraw money following the outbreak. In Japan, foreign investors sold stocks due to COVID-19; firms with high foreign ownership had larger price decreases than firms with low foreign ownership did (Takahashi \& Yamada, 2020).

\section{Research Method and Data}

\subsection{The Model}

This study examines the behavior of foreign investors during the COVID-19 event period. Let $\tilde{y}_{t}$ be the variable that measures foreign investors' trading behavior on day $\mathrm{t}$. It modifies the conditional-regression method (Thompson, 1985; Malatesta, 1986; De Jong, Kemna, \& Kloek 1992) to measure abnormal trading by parameterizing the variables in the regression model in equation (1):

$$
\tilde{y}_{t}=\tilde{\mu}_{t}+\tilde{e}_{t}+\delta_{t} \tilde{v}_{t}
$$

where $\tilde{\mu}_{t}$ is the expected or normal trading level. $\tilde{e}_{t}$ is the error term on a normal day; its expected value and variance are 0.00 and $\sigma_{e}^{2}$, respectively. $\delta_{t}$ is the dummy variable that identifies the event period. $\delta_{t}$ takes the value of 1 if day $\mathrm{t}$ is in the event period, and 0 otherwise. Finally, $\tilde{v}_{t}$ represents the unexpected or abnormal trading level on day $t$ in the event period.

In the conditional regression model, $\tilde{v}_{t}$ is the coefficient that measures abnormal behavior. Regression analyses allow a small number of coefficients. Therefore, the coefficients are the average abnormal behavior. It is possible that important information about the behavior is averaged. In this study, $\tilde{v}_{t}$ is a random variable. It can measure abnormal behavior on each day throughout the event period.

The term $\tilde{e}_{t}+\delta_{t} \tilde{v}_{t}$ in equation (1) is the abnormal variable in the traditional event-study analysis (Fama, Fisher, Jensen, \& Roll, 1969). Significant $\tilde{e}_{t}+\delta_{t} \tilde{v}_{t}$ suggests significant abnormal behavior. It is important to note that $\tilde{e}_{t}$ is a normal random part. Even if $\delta_{t} \tilde{v}_{t}$ is significant but relatively small vis-à-vis $\tilde{e}_{t}$, researchers will not be able to detect its significance. This study does not have this problem. It separates $\delta_{t} \tilde{v}_{t}$ from $\tilde{e}_{t}$ and considers only the $\delta_{t} \tilde{v}_{t}$ component.

\subsection{Model for Normal Trading Behavior}

The normal trading behavior $\tilde{\mu}_{t}$ is unobserved and must be estimated. This study describes $\tilde{\mu}_{t}$ by an autoregressive process of order $1(\operatorname{AR}(1))$ in equation (2):

$$
\tilde{\mu}_{t}=\alpha_{0}+\alpha_{1} \mu_{t-1}+\tilde{\varepsilon}_{t}
$$

where $\alpha_{0}$ and $\alpha_{1}$ are the intercept and $\operatorname{AR}(1)$ coefficient, respectively. $\tilde{\varepsilon}_{t}$ is the error term, whose expected value and variance are 0.00 and $\sigma_{\varepsilon}^{2}$, respectively. This specification is general. This implies the mean-adjusted specification when $\alpha_{1}=\sigma_{\varepsilon}^{2}=0.00$. Brown and Warner (1985) reported that the mean-adjusted specification performs as well as alternatives (Peterson, 1989; Chavali, Alam, \& Rosario, 2020).

\subsection{Model for Abnormal Trading Behavior}

The abnormal behavior $\tilde{v}_{t}$ is not observed. This study describes $\tilde{v}_{t}$ by an AR(1) process with exogenous variables in equation (3). The AR(1) process is modeled for $\tilde{v}_{t}$ after $\tilde{\mu}_{t}$. Exogenous variables are added to help describe $\tilde{v}_{t}$.

$$
\tilde{v}_{t}=\beta_{0}+\beta_{1} v_{t-1}+\beta_{2} \tau_{t}+\beta_{3} C_{t}^{T H}+\beta_{4} C_{t}^{W O}+\tilde{\omega}_{t},
$$

where $\beta_{0}$ is the intercept. $\beta_{1}$ is the $\operatorname{AR}(1)$ coefficient, whereas $\beta_{2}, \beta_{3}$, and $\beta_{4}$ are the response coefficients of abnormal behavior $\tilde{v}_{t}$ to exogenous variables $\tau_{t}, C_{t}^{T H}$, and $C_{t}^{W O}$, respectively. $\tilde{\omega}_{t}$ is the error term, with mean and variance as 0.00 and $\sigma_{\omega}^{2}$, respectively.

The exogenous variables $C_{t}^{T H}$ and $C_{t}^{W O}$ are the numbers of COVID-19 infections in Thailand and the world, respectively, on day $t$. Liu, Manzoor, Wang, Zhang, and Manzoor (2020) found that these variables explain abnormal returns on the stock markets in 21 affected countries.

$\tau_{t}$ is a dummy variable. It takes the value of 1.00 for the period from the first event day to one day prior to when Thailand's Department of Disease Control and the WHO started to report COVID-19 daily statistics, and 0.00 otherwise (Note that the fact that the two authorities did not report the statistics prior to the day of first statistics does not imply that there were no infections.) The coefficient $\beta_{1}$ is the average response of $\tilde{v}_{t}$ to the missing COVID-19 data.

\subsection{Model Estimation}

This study applies a state-space model, in which the observed trading behavior is related to the unobserved normal and abnormal behaviors in the measurement equation (1). The unobserved $\tilde{\mu}_{t}$ and $\tilde{v}_{t}$ are considered state variables, whose stochastic behaviors are described by transition equations (2) and (3). The study assumes a zero correlation between error terms $\tilde{\varepsilon}_{t}$ and $\tilde{\omega}_{t}$. This assumption is justified by the fact that abnormal behavior is zero under the null hypothesis. Transition equations (2) and (3) can be rewritten as a system of equations in (4). 


$$
\begin{aligned}
{\left[\begin{array}{c}
\tilde{\mu}_{t} \\
\tilde{v}_{t}
\end{array}\right]=} & {\left[\begin{array}{c}
\alpha_{0} \\
\beta_{0}
\end{array}\right]+\left[\begin{array}{cc}
\alpha_{1} & 0 \\
0 & \beta_{1}
\end{array}\right]\left[\begin{array}{c}
\mu_{t-1} \\
v_{t-1}
\end{array}\right] } \\
& +\left[\begin{array}{ccc}
0 & 0 & 0 \\
\beta_{2} & \beta_{3} & \beta_{4}
\end{array}\right]\left[\begin{array}{c}
\tau_{t} \\
C_{t}^{T H} \\
C_{t}^{W O}
\end{array}\right]+\left[\begin{array}{c}
\tilde{\varepsilon}_{t} \\
\tilde{\omega}_{t}
\end{array}\right],
\end{aligned}
$$

where the covariance matrix of $\left[\begin{array}{c}\tilde{\varepsilon}_{t} \\ \tilde{\omega}_{t}\end{array}\right]$ is $\left[\begin{array}{cc}\sigma_{\varepsilon}^{2} & 0 \\ 0 & \sigma_{\omega}^{2}\end{array}\right]$.

The state-space model in equations (1) and (4) is estimated by Kalman filtering (Harvey, 1990). It is a recursive procedure for computing the optimal estimators of time t's unobserved state variables $\tilde{\mu}_{t}$ and $\tilde{v}_{t}$, based on observed information $\tilde{y}_{t}$ available up to and including time t. This recursive procedure consists of predicting and updating phases. In the predicting phase, the state variables and prediction error variances are estimated using the observed information from the previous period. Once the new information is available, the estimated state variables are updated. In addition to parameter estimates, Kalman filtering returns the estimates and standard errors of the unobserved state variables $\tilde{\mu}_{t}$ and $\tilde{v}_{t}$.

Kalman filtering was applied in event-study analyses by Brocket, Chen, and Garven (1994), Buckland and Fraser (2000), and Khanthavit (2019). However, detailed treatments of abnormal variables differ. The approach in this study follows Khanthavit (2019). Brocket et al. (1994) and Buckland and Fraser's (2000) approaches bias for nonsignificance.

\subsection{Event and Estimation Periods}

\subsubsection{The COVID-19 Event Period}

The COVID-19 pandemic involves a series of events. In event studies of stock price reactions to COVID-19, researchers proposed different choices for event dates. Aravind and Manojkrishnan (2020) and Khanthavit (2020) chose the date of the earliest detection of the disease; Ramelli and Wagner (2020) were interested in China's first COVID-19 report to the WHO, China's report of human-tohuman transmission of the virus, and Italy's announcement of the lockdown measure; whereas Kim, Kim, Lee, and Tang (2020) chose the date the disease became known to the media.

As in Aravind and Manojkrishnan (2020) and Khanthavit (2020), the first event in this study is the earliest detection of COVID-19 in China on Sunday, November 17, 2019. Because November 17, 2019, is a holiday, the first day of the event period is the following trading day: Monday, November 18,
2019. At the time of this writing, the COVID-19 pandemic has not ended. The last day of the event period is Monday, May 18, 2020, the last day of the available sample. The event period is 122 trading days.

Unlike in previous studies, the event period in this study does not include pre-event samples. The study focuses on the trading behavior of foreign investors in the time of COVID-19. COVID-19 did not exist in the pre-event period before November 17, 2019. Moreover, Khanthavit (2020) reported that Thai stock did not react to COVID-19 in the pre-event period.

\subsubsection{Pre-event Period}

Typical lengths of the pre-event period range from 100 to 300 days (Peterson, 1989). This study chose the longest period of 300 days for accurate parameter estimation (Salinger, 1992). The period begins Tuesday, August 28, 2018, and ends Friday, November 15, 2019. Unlike traditional event studies, estimation of the conditional regression model and the model in this study uses a full sample period, which combines the pre-event and event periods together.

\subsection{Analysis of Foreign Investors' Abnormal Trading Behavior}

\subsubsection{Significance of Abnormal Trading Behavior}

Before testing for the trading strategy, herd behavior, and market destabilization, the study checks for significant abnormal behavior. From transition equation (4), if the behavior is not significant, $\beta_{0}=\beta_{1}=\beta_{2}=\beta_{3}=\sigma_{\omega}^{2}=0.00$. The study is aware that, in addition to parameter estimates, Kalman filtering returns the estimates and standard errors of $\tilde{v}_{t}$. Non-significance implies that $\sum_{t=1}^{T} \tilde{v}_{t}=0$, where $t=1(t=T)$ is the first (last) day of the event period. The hypothesis test of $\sum_{t=1}^{T} \tilde{v}_{t}=0$ is performed using a Wald test. Under the null hypothesis, the Wald statistic is distributed as a chi-square variable of degrees of freedom.

\subsubsection{Trading Strategy, Herd Behavior, and Market Destabilization}

The study follows Hood et al. (2013) and uses a vector autoregressive model of order $\mathrm{p}(\operatorname{VAR}(\mathrm{p}))$ of the stock return $\tilde{r}_{t}$ and abnormal trading behavior $\tilde{v}_{t}$ to examine trading strategy, herd behavior, and market destabilization of foreign investors. The $\operatorname{VAR}(p)$ model is equation (5). 


$$
\left[\begin{array}{c}
\tilde{r}_{t} \\
\tilde{v}_{t}
\end{array}\right]=\left[\begin{array}{c}
a_{0} \\
b_{0}
\end{array}\right]+\sum_{i=1}^{p}\left[\begin{array}{cc}
a_{i}^{r} & a_{i}^{v} \\
b_{i}^{r} & b_{i}^{v}
\end{array}\right]\left[\begin{array}{c}
\tilde{r}_{t-i} \\
\tilde{v}_{t-i}
\end{array}\right]+\left[\begin{array}{c}
\tilde{z}_{t}^{r} \\
\tilde{z}_{t}^{v}
\end{array}\right]
$$

where $\left[\begin{array}{l}a_{0} \\ b_{0}\end{array}\right]$ is the vector of the intercepts and $\left[\begin{array}{ll}a_{i}^{r} & a_{i}^{v} \\ b_{i}^{r} & b_{i}^{v}\end{array}\right]$ is the matrix of order i coefficients. $\left[\begin{array}{c}\tilde{z}_{t}^{r} \\ \tilde{z}_{t}^{v}\end{array}\right]$ is the vector of regression errors, whose covariance matrix is $\Omega$.

The order p is not known and must be estimated. This study chooses $\mathrm{p}$ using the $\operatorname{VAR}\left(\mathrm{p}^{*}\right)$ model that gives the minimum Bayesian information criterion (BIC) (Schwarz, 1978). $\operatorname{BIC}(\mathrm{p})=\operatorname{Ln}|\Omega|+\frac{\operatorname{Ln}(T)}{T} 4 p$. The statistic consistently estimates $p$ and is widely applied in the literature (Zivot \& Wang, 2006).

It is difficult to make direct inferences from the coefficient estimates in equation (5). A better approach to analyze the reaction of the variables $\tilde{r}_{t}$ and $\tilde{v}_{t}$ to corresponding independent shocks $\left[\begin{array}{c}\tilde{u}_{t}^{r} \\ \tilde{u}_{t}^{v}\end{array}\right]$ is to trace the system's moving average representation (Karolyi, 2002). $\left[\begin{array}{c}\tilde{u}_{t}^{r} \\ \tilde{u}_{t}^{v}\end{array}\right]$ is a vector of independent shocks, whose covariance matrix is an identity matrix. $\left[\begin{array}{c}\tilde{z}_{t}^{r} \\ \tilde{z}_{t}^{v}\end{array}\right]=\left[\begin{array}{cc}\varphi_{r, r} & 0 \\ \varphi_{r, v} & \varphi_{v, v}\end{array}\right]\left[\begin{array}{c}\tilde{u}_{t}^{r} \\ \tilde{u}_{t}^{v}\end{array}\right]$ such that $\left[\begin{array}{cc}\varphi_{r, r} & 0 \\ \varphi_{r, v} & \varphi_{v, v}\end{array}\right]\left[\begin{array}{cc}\varphi_{r, r} & 0 \\ \varphi_{r, v} & \varphi_{v, v}\end{array}\right]=\Omega$. This study follows Karolyi (2002) to force the response pattern from the stock return to the trading behavior by the Cholesky factorization specification $\left[\begin{array}{cc}\varphi_{r, r} & 0 \\ \varphi_{r, v} & \varphi_{v, v}\end{array}\right]$.

Iterative substitution of the terms on the right-hand side of equation (5) gives a moving-average representation of infinite orders in equation (6):

$$
\left[\begin{array}{c}
\tilde{r}_{t} \\
\tilde{v}_{t}
\end{array}\right]=\sum_{s=0}^{\infty} \Phi_{s}\left[\begin{array}{cc}
\varphi_{r, r} & 0 \\
\varphi_{r, v} & \varphi_{v, v}
\end{array}\right]\left[\begin{array}{c}
\tilde{u}_{t-s}^{r} \\
\tilde{u}_{t-s}^{v}
\end{array}\right] .
$$

The $(\mathrm{i}, \mathrm{j})^{\text {th }}$ component of matrix $\Phi_{s}$ measures the response of the $\mathrm{i}^{\text {th }}$ variable in $s$ days to a unit random shock in the $\mathrm{j}^{\text {th }}$ variable. The components $\mathrm{i}, \mathrm{j}=1$ and $\mathrm{i}, \mathrm{j}=2$ correspond to the variables $\widetilde{Z}_{t}^{r}$ and $\widetilde{Z}_{t}^{v}$, respectively.
Finally, define $\Psi_{s}=\Phi_{s}\left[\begin{array}{cc}\varphi_{r, r} & 0 \\ \varphi_{r, v} & \varphi_{v, v}\end{array}\right]$. The $(\mathrm{i}, \quad \mathrm{j})^{\text {th }}$ component of matrix $\Psi_{s}$ is the impulse response of the $\mathrm{i}^{\text {th }}$ variable in $s$ days to a shock of one standard deviation (S.D.) in the $\mathrm{j}^{\text {th }}$ variable. The components $\mathrm{i}, \mathrm{j}=1$ and $\mathrm{i}, \mathrm{j}=2$ correspond to variables $\tilde{u}_{t-s}^{r}$ and $\tilde{u}_{t-s}^{v}$, respectively.

If foreign investors use a positive-feedback strategy and trade with herd behavior, destabilization of the market is possible (Cho et al., 1999). This study infers the trading strategy, herd behavior, and market destabilization from the significance and pattern of impulse responses.

First, if $\Psi_{s}(2,1)$ is positive and significant, foreign investors are positive-feedback investors (Karolyi, 2002). They buy more stocks after a price increase. However, if $\Psi_{s}(2,1)$ is negative and significant, they follow a contrarian strategy.

Second, the study concludes that foreign investors exhibit herd behavior if $\Psi_{s}(2,1)$ is positive and significant (Richards, 2005). The investors buy more stocks if they recognize others buying stocks before them.

Third, the fact that foreign investors use a positivefeedback strategy and engage in herd behavior does not imply that their trading destabilizes the market. The trades may not be powerful enough to move the market, or they may correspond to an autoregressive fundamental (Cho et al., 1999). To demonstrate that foreign investors' trades destabilize the market, $\Psi_{1}(1,2)$ must be positive and significant and $\Psi_{s>1}(1,2)$ must alternate in sign (Karolyi, 2002). Foreign buying increases the price. Because buying is not based on information, the price reverses, and thus, there is no permanent price increase.

\subsection{The Data}

The sample market is SET. The data are daily from Tuesday, August 28, 2018, to Monday, May 18, 2020 (422 trading-day observations). Foreign investors' trading behavior is measured by net buying volume divided by market capitalization. The ratio is scaled up by 10,000 owing to its small size. The realized stock return is the logged return computed from closing SET indexes. The stock return sample covers only the event period from Monday, November 18, 2019, to Monday, May 18, 2020 (122 trading-day observations). The trading volume, market capitalization, and SET index data are from the SET database. The study retrieved the numbers of infections for Thailand and the world from Thailand's Department of Disease Control (https://data.go.th/dataset/covid-19-daily) and the Global Change Data Lab (https://ourworldindata. org/coronavirus-source-data), respectively. The samples 
are from Tuesday, December 31, 2019, to Monday, May 18, 2020 (140 calendar-day observations). However, in the analysis, these samples are trading-day observations.

\section{Empirical Results}

\subsection{Descriptive Statistics}

Table 1 reports the descriptive statistics of net buying volume, Thailand and world infections, and the SET-index return. For foreign investors' net buying volume, statistics for the full and pre-event samples are close. The variables are positively skewed and have fat-tailed distribution. The variable in the event sample behaves differently. It is negatively skewed and has less fat-tailed distribution. Its maximum value is smaller than those in the full and estimation periods. These statistics suggest that foreign investors tended to buy less or even became net sellers most days in the event period. The Jarque-Bera statistic rejects the normality hypothesis for all three periods.

Although Thailand is the first country outside China to experience COVID-19 infection, the country's control of the disease has been successful. Compared to global statistics, Thailand has few cases. The study uses infection cases instead of logged values (Liu et al., 2020) in the estimation, because there were no infections in the early days of the outbreak. Moreover, successful disease control in Thailand has reduced the number of infections to zero in recent days.

The average stock return is negative; the return is negatively skewed and fat-tailed. The negative average and skewness reflect a falling market during COVID-19. Finally, the Jarque-Bera statistics reject the normality hypothesis for the stock return and infections at the $99 \%$ confidence level. Despite non-normality of the observed variables, Kalman filtering is usable. Given the linear relationship of the observed variables and the dynamics of the state variables in state-space equations (1) and (4), the Kalman filter is optimal; it returns the minimum mean square linear estimates (Kellerhals, 2001).

\subsection{Parameter Estimates and Tests for Significant Abnormal Trading Behavior}

This study estimates the state-space model in equations (1) and (4) using the Kalman filtering technique. The estimates are reported in Table 2. The coefficient $a_{1}$ and standard deviation $\sigma_{\omega}$ are positive and significant, suggesting that the expected net buying volume is random. It follows a positive AR(1) process. This result supports the proposed AR(1) specification for the expected volume over the constant-mean specification commonly used in event-study analyses.

The intercept $b_{0}$ and standard deviation $\sigma_{\omega}$ are significant. This finding suggests that foreign investors' abnormal trading volumes are significant. The coefficients $b_{2}$ and $b_{3}$ are negative; thus, foreign investors react negatively to Thailand and the world's infections. However, the reactions are not significant. The coefficient $b_{1}$ is not significant either; the seriousness of the virus situation before the WHO reported infection statistics does not add to the abnormal trading volume over the $b_{0}$ level.

Table 1: Descriptive Statistics

\begin{tabular}{|c|c|c|c|c|c|c|}
\hline \multirow[b]{2}{*}{ Statistics } & \multicolumn{3}{|c|}{ Foreign Investors' Net Buying Volume } & \multicolumn{2}{|c|}{ COVID-19 Infections ${ }^{d}$} & \multirow[b]{2}{*}{ Stock Return } \\
\hline & Full Sample ${ }^{a}$ & $\begin{array}{l}\text { Pre-event } \\
\text { Sample }^{\mathrm{b}}\end{array}$ & $\begin{array}{c}\text { Event-Period } \\
\text { Sample }^{c}\end{array}$ & Thailand & World & \\
\hline Average & -0.2003 & -0.2115 & -1.2955 & 21.6500 & $33,425.0786$ & -0.0018 \\
\hline Standard Deviation & 1.3525 & 1.3518 & 1.5810 & 38.3848 & $37,236.8905$ & 0.0235 \\
\hline Skewness & 0.1773 & 0.1991 & -1.2357 & 2.1065 & 0.4735 & -1.5621 \\
\hline Excess Kurtosis & 6.7359 & 6.7609 & 2.1477 & 3.7852 & -1.6076 & 8.0705 \\
\hline Maximum & 7.4988 & 7.4988 & 1.5525 & 188 & 101,445 & 0.0765 \\
\hline Minimum & -7.2066 & -7.2066 & -7.3409 & 0 & 0 & -0.1143 \\
\hline $\begin{array}{l}\text { Jarque-Bera } \\
\text { Statistic }\end{array}$ & $8.00 \mathrm{E}+02^{* * * *}$ & $57.33 \mathrm{E}+2^{* * *}$ & $54.4938^{* * *}$ & $1.87 \mathrm{E}+02^{*+*}$ & $20.3068^{* * *}$ & $3.81 \mathrm{E}+02$ \\
\hline
\end{tabular}

"," ", and "** indicate significance at the $90 \%, 95 \%$, and 99\% significance levels, respectively. ${ }^{\text {a }}=$ from Tuesday, August 28,2018 , to Monday, May 18, 2020 (422 trading-day observations), ${ }^{\mathrm{b}}=$ from Tuesday, August 28, 2018, to Friday, November 15, 2019 (300 tradingday observations), ${ }^{c}=$ from Monday, November 18, 2019, to Monday, May 18, 2020 (122 trading-day observations), and ${ }^{\mathrm{d}}=$ from Tuesday, December 31, 2019, to Monday, May 18, 2020 (140 calendar-day observations). 
The Kalman filter returns the $\tilde{v}_{t}$ estimate and its $t$ statistics for the event period. This study uses these statistics to conduct an alternative test for significant abnormal trading behavior. Abnormal trading behavior is not significant when $\sum_{t=1}^{T} \tilde{v}_{t}=0$. The event period is $T=122$ days. Under the null hypothesis, the Wald statistic must be distributed as a chisquare variable with 122 degrees of freedom. The resulting Wald statistic is 384.3408 ; its p-value is zero, and the nonsignificance hypothesis is rejected. The result for significant $b_{0}$ and $\sigma_{\omega}$, together with a significant Wald statistic, leads to the conclusion that foreign investors' abnormal trading behavior is significant.

Table 2: Model Parameters

\begin{tabular}{|c|c|}
\hline Parameters & Estimates \\
\hline $\mathrm{a}_{0}$ & -0.0236 \\
\hline $\mathrm{a}_{1}$ & $0.8872^{* * *}$ \\
\hline $\mathrm{b}_{0}$ & $-1.1131^{*}$ \\
\hline $\mathrm{b}_{1}$ & 0.0731 \\
\hline $\mathrm{b}_{2}$ & 0.5289 \\
\hline $\mathrm{b}_{3}$ & -0.1607 \\
\hline $\mathrm{b}_{4}$ & -0.1165 \\
\hline$\sigma_{\mathrm{e}}$ & $0.9908^{* * *}$ \\
\hline$\sigma_{\varepsilon}$ & $0.4207^{* * *}$ \\
\hline$\sigma_{\omega}$ & $0.6751^{* * *}$ \\
\hline
\end{tabular}

*and ${ }^{* * *}$ indicate significance at the $90 \%$ and $99 \%$ significance levels, respectively.

\subsection{Tests for Investment Strategy, Herd Behavior, and Market Destabilization}

Foreign investors' abnormal buying volume is significant. To check for its effects on the SET, a VAR(1) model is estimated in equation (5). A lag of $\mathrm{p}=1$ is chosen, because it corresponds to the smallest BIC statistic of -3.3743 . The parameter estimates are reported in Table 3.

The stock return and abnormal volume are autocorrelated. The lagged return cannot explain the current abnormal volume and vice versa. The resulting impulse responses are plotted in Figure 1. The solid line represents the level of impulse responses. The dotted lines identify a two-S.D. band surrounding the response. The response is significant if the band does not include zero.

In Sub-figure 1.1, the abnormal trading volume responds negatively to the rising price. However, the impulse response is not significant. Thus, the study cannot conclude that the negative response reflects a contrarian strategy; rather, it concludes that the strategy is not a positive-feedback strategy.

Table 3: Parameter Estimates for the VAR(1) Model

\begin{tabular}{|l|c|c|}
\hline \multirow{2}{*}{ Regressors } & \multicolumn{2}{|c|}{ Regression } \\
\cline { 2 - 3 } & Return (t) & $\begin{array}{c}\text { Abnormal Net } \\
\text { Buying (t) }\end{array}$ \\
\hline Return (t-1) & $-0.1714^{*}$ & -1.3174 \\
\hline $\begin{array}{l}\text { Abnormal Net } \\
\text { Buying (t-1) }\end{array}$ & 0.0032 & $0.4602^{* * *}$ \\
\hline Constant & 0.0014 & $-0.6000^{* * *}$ \\
\hline
\end{tabular}

" and "** indicate significance at the $90 \%$ and $99 \%$ significance levels, respectively.

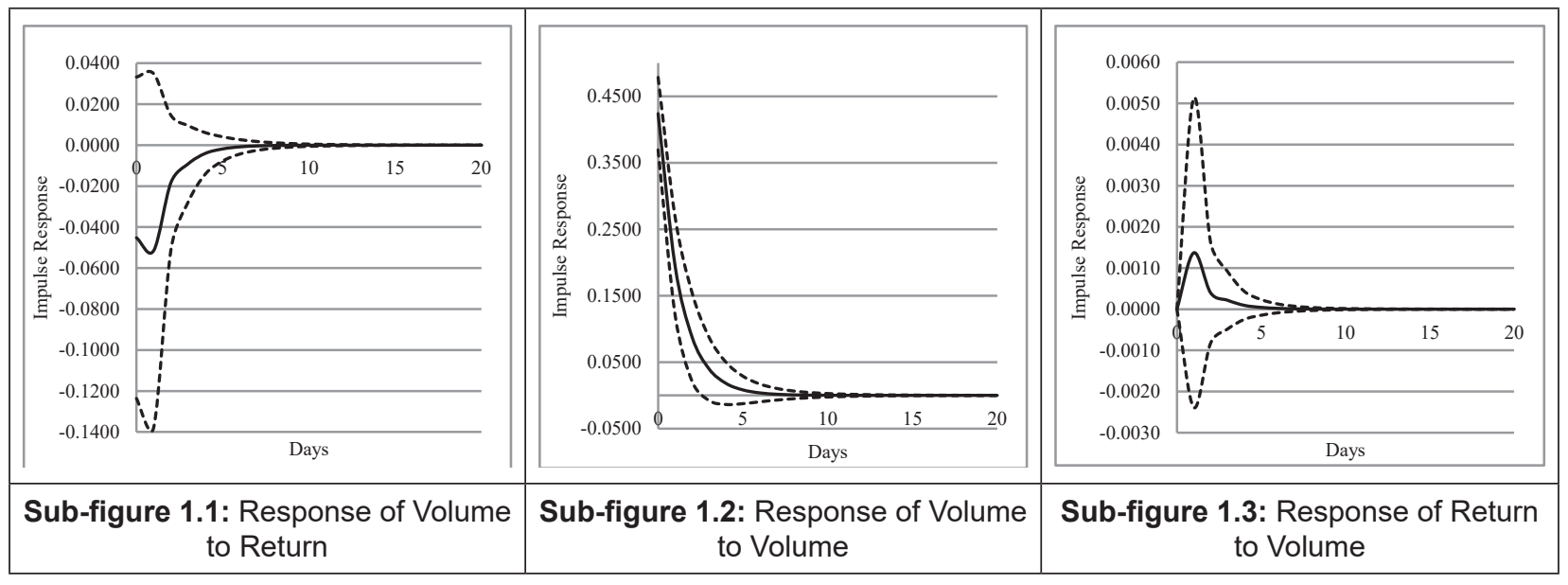

Figure 1: Impulse Response Analysis of Foreign Investors' Abnormal Net Buying Volume 




Figure 2: Impulse Response Analysis of Foreign Investors' Normal Net Buying Volume

Sub-figure 1.2 illustrates the impulse response of abnormal volume to its lag is significant up to two days. This evidence is consistent with self-herd behavior (Karolyi, 2002).

The study checks whether abnormal trade destabilizes SET. In Sub-figure 1.3, all impulse responses are positive but none are significant. The fact that the responses do not change sign implies that abnormal trading is not marketdestabilizing. Non-significance suggests that the volume can move the price but not significantly nor permanently. Abnormal trade does not bring information to the market.

\section{Discussion}

\subsection{Contribution to Realized Buying Volume}

This study examines how foreign investors' normal trading behavior is altered by significant abnormal behavior. To answer, a VAR(p) model is estimated and impulse responses of the normal buying volume and stock returns are analyzed using full sample. Normal volume is observed from Tuesday, August 28, 2018, to Friday, November 15, 2019. It is not observed during the event period. Therefore, this study appends the series from Monday, November 18, 2019, to Monday, May 18, 2020, by Kalman-filtering estimates. The lag $\mathrm{p}=1$ is optimal, with a BIC statistic of -1.6488 . The Cholesky factorization imposes the response pattern from the stock return to normal volume. The impulse responses are plotted in Figure 2.

In Sub-figure 2.1, the response of the normal volume to the return shock is positive. However, this is not significant. Normally, foreign investors do not follow a positivefeedback strategy. Because the impulse responses for normal and abnormal volumes have opposite signs, they cancel.
The cancellation effect is small; the size of the responses of abnormal volume is smaller than the size of normal volume.

Sub-figure 2.2 suggests that foreign investors are selfherding. The impulse response is positive and significant for two days. The response for the abnormal volume is positive and significant for two days. This helps intensify the self-herd behavior of foreign investors in the COVID-19 period.

Herd behavior may not necessarily be irrational (Cho et al., 1999). In Table 3, the return is negatively autocorrelated. Sub-figure 2.1 confirms that abnormal buying is against previous price drops. However, under these circumstances, self-herding may be irrational or irrational with respect to the negative AR(1) price. It is irrational because self-herding is money-losing; however, as foreign investors represent a large proportion of the SET, trade can move stock prices against them. Self-herding is rational as investors split orders to lessen price impacts (Richards, 2005).

The impulse response of the return to normal-volume shock is positive and significant for day one. No price reversal is observed, and the price increase is permanent. Foreign investors' normal volume brings information to the SET. This finding is consistent with findings for other markets (Kim \& Cheon, 2004).

Although not significant, the impulse-response pattern of stock return to abnormal volume in Sub-figure 1.3 is analogous to normal volume in Sub-figure 2.3. Abnormal volume is not informative, but adds volatility to stock returns. The study measures volatility induced by abnormal behavior by regressing the stock return on normal and abnormal volumes in the event period. Next, it computes the percentage shares of return variance, which is explained by normal and abnormal volumes. The share of abnormal volume is $7.09 \%$, which is almost equal to the share of normal volume of $10.41 \%$. 
Significance of the shares is at $95 \%$ and $99 \%$ confidence levels, respectively. Increased volatility can be explained by information blockade to foreign investors (Hong, 2016); foreign investors lack information about COVID-19 situations in Thailand as suggested by their self-herd behavior (Sias, 2004).

\subsection{Significant Abnormal Net Buying Volume to Events}

The COVID-19 situation has evolved, with important events identified for Thailand and the world. This study adopts these events from Khanthavit (2020) and tests for significant abnormal volume on the event days and cumulative abnormal volume during an 11-day period surrounding the event days. The 11-day period includes the event day and five days before and after the event day. The results are reported in Table 4.

For most events, the cumulative abnormal volume is negative and significant at high confidence levels. This result is expected because the intercept $b_{0}$ for the daily abnormal volume is negative and significant. Foreign investors were aware of the seriousness of COVID-19. Investors reacted negatively and significantly to the country's first COVID-19 death. In Khanthavit (2020), most stock markets in the sample reacted negatively to the first and second extensive global media coverage on January 27, 2020, and February 24,2020 . This study finds that foreign investors on the SET reacted negatively and significantly at the $90 \%$ confidence level to the first media coverage. The negative reaction to the second media coverage is not significant. However, its $p$ value is small at 0.1148 .

\subsection{Positive-Feedback Investors}

Previous studies (Cho et al., 1999; Karolyi, 2002; Hood et al., 2013) reported that foreign investors are positivefeedback investors. This study does not find evidence to support a positive-feedback hypothesis for foreign investors on the SET for the full period or the COVID-19 period. The result is robust for normal and abnormal volumes. The explanation can be stock price behavior. The study conducted an $\mathrm{AR}(1)$ regression analysis for stock return in the pre-event period. The AR(1) coefficient is -0.0084 . It is small and not significant; the positive feedback strategy is not a successful strategy on the SET.

Table 4: Foreign Investors' Abnormal Trading Volume on Event Days and during 11-Day Event Periods

\begin{tabular}{|c|c|c|c|c|}
\hline \multicolumn{2}{|l|}{ Day } & \multirow{2}{*}{ Event Description } & \multicolumn{2}{|c|}{$\begin{array}{l}\text { Abnormal Net Buying } \\
\text { Volume }\end{array}$} \\
\hline Occurrence & Event & & $\begin{array}{l}\text { On Event } \\
\text { Day }\end{array}$ & $\begin{array}{c}\text { In 11-day } \\
\text { Event Period }\end{array}$ \\
\hline $12 / 8 / 19^{H}$ & $12 / 9 / 19$ & First official confirmed COVID-19 case in China & -0.4845 & -8.0483 \\
\hline $12 / 31 / 19^{H}$ & $1 / 2 / 20$ & $\begin{array}{l}\text { China informed the WHO of patients with mysterious } \\
\text { pneumonia }\end{array}$ & -0.9239 & -8.6626 \\
\hline $1 / 11 / 20^{H}$ & $1 / 13 / 20$ & China and the world's first COVID-19 death & \multirow[b]{2}{*}{-0.9337} & \multirow[b]{2}{*}{$-10.8513^{*}$} \\
\hline $1 / 13 / 20$ & $1 / 13 / 20$ & $\begin{array}{l}\text { Thailand's first COVID-19 case and first infection case } \\
\text { outside China }\end{array}$ & & \\
\hline $1 / 20 / 20$ & $1 / 20 / 20$ & $\begin{array}{l}\text { China publicly conceded human-to-human transmission of } \\
\text { the COVID-19 virus } \\
\text { The WHO issued its first situation report on COVID-19 }\end{array}$ & -0.8954 & $-11.2435^{* * *}$ \\
\hline $1 / 27 / 20$ & $1 / 27 / 20$ & First extensive media coverage & $-1.2766^{*}$ & $-11.0800^{* * * *}$ \\
\hline $1 / 30 / 20$ & $1 / 30 / 20$ & $\begin{array}{l}\text { The WHO declared a global public-health emergency for } \\
\text { COVID-19 }\end{array}$ & -0.9966 & $-11.9671^{* * *}$ \\
\hline $2 / 3 / 20$ & $2 / 3 / 20$ & $\begin{array}{l}\text { The Philippines' first COVID-19 death and first COVID-19 } \\
\text { death case outside China }\end{array}$ & -0.7166 & $-11.6796^{\star * *}$ \\
\hline $2 / 24 / 20$ & $2 / 24 / 20$ & Second extensive media coverage & -1.0646 & $-10.8303^{* * *}$ \\
\hline $3 / 1 / 20^{\mathrm{H}}$ & $3 / 2 / 20$ & Thailand's first COVID-19 death & $-1.4657^{* *}$ & $-10.9054^{* * *}$ \\
\hline $3 / 11 / 20$ & $3 / 11 / 20$ & The WHO declared COVID-19 a global pandemic & -1.0145 & $-13.4351^{* * *}$ \\
\hline
\end{tabular}

${ }^{\mathrm{H}}$ indicates holiday on which the stock market did not trade. ${ }^{*},{ }^{* *}$, and ${ }^{* * *}$ indicate significance at the $90 \%, 95 \%$, and $99 \%$ significance levels, respectively. 


\subsection{Robustness Check}

Impulse response analyses can be sensitive to the Cholesky factorization specification. To check for robustness, the study re-estimates a VAR(1) model in equation (5). Factorization imposes a response pattern from trading behavior to stock returns (Dahlquist \& Robertsson, 2004). The results are similar to those in Figure 1.

\section{Conclusion}

Foreign investors' trading behavior is important for researchers and local authorities. In this study, the behavior of foreign investors in Thailand's stock market is examined in the time of COVID-19. The COVID-19 pandemic has brought health and economic disaster to Thailand and the world. As foreign investors are a major investor group in the market, it is important to understand how these investors behave during the COVID-19 period.

COVID-19 is an abnormal event. Therefore, this study focuses on foreign investors' abnormal trading behavior. It extends the conditional-regression approach to event studies and extracts the unobserved abnormal component of trading volume by Kalman filtering. The abnormal volume is negative and significant. Its estimate is analyzed with the stock return by a vector autoregressive model; the study infers foreign investors' trading strategy, herd behavior, and market-destabilizing role from the VAR's impulse responses. The study does not find evidence to support the positivefeedback strategy or market-destabilizing role. However, foreign investors exhibit self-herd behavior.

Additional to foreign investors, local-individual, localinstitutional, and proprietary investors trade actively on the SET. Their buying and selling contribute to price movement, price discovery, market stability, and market depth. This study focuses only on foreign investors' behavior, disregarding remaining groups. In the time of COVID-19, other investor behaviors should be examined. This study leaves normal and abnormal behavior of local-individual, local-institutional, and proprietary investors for future research.

\section{References}

Anuchitworawong, C., \& Thampanishvong, K. (2015). Determinants of foreign direct investment in Thailand: Does natural disaster matter? International Journal of Disaster Risk Reduction, 14(3), 312-321. https://doi.org/10.1016/j. ijdrr.2014.09.001

Aravind, M., \& Manojkrishnan, C. G. (2020). COVID-19: Effect on leading pharmaceutical stocks listed with NSE. International Journal of Research in Pharmaceutical Sciences, 11(Supplement 1), 31-36. https://doi.org/10.26452/ijrps. v11iSPL1.2014
Bangkok Post. (2020). Thai stocks slide most in 11 years. Bangkok Post. Retrieved from https://www.bangkokpost.com/ business/1877424/thai-stocks-slide-most-in-11-years

Bertaut, C. C., \& Laurie, P. (2009). The financial crisis and U.S. cross-border financial flows. Federal Reserve Bulletin, 95, A147-A165. Retrieved from https://www.federalreserve.gov/ pubs/bulletin/2009/pdf/Crossborder09.pdf

Brennan, M., \& Cao, H. (1997). International portfolio investment flows. Journal of Finance, 52(5), 1851-1880. https://doi. org/10.1111/j.1540-6261.1997.tb02744.x

Brockett, P. L., Chen, H. M., \& Garven, J. R. (1994). Event study methodology: A new and stochastically flexible approach. Working Paper. University of Texas, Austin, TX. Retrieved from https://www.researchgate.net/profile/Patrick_Brockett/ publication/23739880_Event_Study_Methodology_A_ New_and_Stochastically_Flexible_Approach/ links/00463518c17b886a3d000000.pdf

Brown, S. J., \& Warner, J. B. (1985). Using daily stock returns: The case of event studies. Journal of Financial Econometrics. 14(1), 3-31. https://doi.org/10.1016/0304-405X(85)90042-X

Buckland, R., \& Fraser, P. (2000). Risk and returns sensitivity in UK electricity utilities, 1990-1999. Aberdeen Papers in Accountancy, Finance and Management No. 00-1. University of Aberdeen, Aberdeen, Scotland. Retrieved from http://dx.doi. org/10.2139/ssrn.243029

Chavali, K., Alam, M., \& Rosario, S. (2020). Stock market response to elections: An event study method. Journal of Asian Finance, Economics and Business, 7(5), 9-18. https://doi.org/10.13106/ jafeb.2020.vol7.no5.009

Choe, H., Kho, B. C., \& Stulz, R. M. (1999). Do foreign investors destabilize stock markets? The Korean experience in 1997. Journal of Financial Economics, 54(2), 227-264. https://doi. org/10.1016/S0304-405X(99)00037-9

Civilize, S., Wongchoti, U., \& Young, M. (2015). Military regimes and stock market performance. Emerging Markets Review, 22, 76-95. https://doi.org/10.1016/j.ememar.2015.01.001

Dahlquist, M., \& Robertsson, G. (2004). A note on foreigners' trading and price effects across firms. Journal of Banking and Finance, 28(3), 615-632. https://doi.org/10.1016/S03784266(03)00036-0

De Jong, F., Kemna, A., \& Kloek, T. (1992). A contribution to event study methodology with an application to the Dutch stock market. Journal of Banking and Finance, 16(1), 11-36. https:// doi.org/10.1016/0378-4266(92)90076-C

De Long, J. B., Shleifer, A., Summers, L. H., \& Walkmann, R. J. (1990). Positive feedback investment strategies and destabilizing rational speculation. Journal of Finance, 45(2), 379- 395. https://doi.org/10.1111/j.1540-6261.1990.tb03695.x

Errunza, V. (2001). Foreign portfolio equity investments, financial liberalization, and economic development. Review of International Economics, 9(4), 703-726. https://doi. org/10.1111/1467-9396.00308 
Fama, E. F., Fisher, J., Jensen, M. C., \& Roll, R. (1969). The adjustment of stock prices to new information. International Economic Review, 10(1), 1-21.https://doi.org/10.2307/2525569

Froot, K., O'Connell, P., Seasholes, M. (2001). The portfolio flows of international investors. Journal of Financial Economics, 59(2), 151- 193. https://doi.org/10.1016/S0304-405X(00)00084-2

Harvey, A. C. (1990). Forecasting Structural Time Series Models and the Kalman Filter. Cambridge, UK: Cambridge University Press.

Hong, H. (2016). Information cascade and share market volatility: A Chinese perspective. Journal of Asian Finance, Economics and Business, 3(4), 17-24. https://doi.org/10.13106/jafeb.2016. vol3.no4.17

Hood, M., Kamesaka, A., Nofsinger, J., \& Tamura, T. (2013). Investor response to a natural disaster: Evidence from Japan's 2011 earthquake. Pacific-Basin Finance Journal, 25, 240-252. https://doi.org/10.1016/j.pacfin.2013.09.006

Jeon, J. Q., \& Moffett, C. M. (2010). Herding by foreign investors and emerging market equity returns: Evidence from Korea. International Review of Economics and Finance, 19(4), 698-710. https://doi.org/10.1016/j.iref.2010.03.001

Karolyi, G. A. (2002). Did the Asian financial crisis scare foreign investors out of Japan? Pacific-Basin Finance Journal, 10(4), 411-422. https://doi.org/10.1016/S0927-538X(02)00067-7

Kellerhals, B. P. (2001). Financial Pricing Models in Continuous Time and Kalman Filtering. New York, NY: Springer-Verlag.

Khanthavit, A. (2019). A Kalman filtering approach to event study analysis when performance variables are nonstationary. Working Paper. Thammasat University, Bangkok, Thailand. Retrieved from https://www.researchgate.net/publication/334025651_A_ Kalman_Filtering_Approach_to_Event_Study_Analysis_ When_Performance_Variables_are_Nonstationary

Khanthavit, A. (2020). World and national stock market reactions to COVID-19. ABAC Journal, 40(2), 1-20. Retrieved from http:// www.assumptionjournal.au.edu/index.php/abacjournal/article/ view/4753/2736

Kim, D. S., \& Cheon, Y. (2004). Foreign investors vs. domestic investors, who are better informed investors? Asia-Pacific Journal of Financial Studies, 33(2), 1-44.

Kim, J., Kim, J., Lee, S. K., \& Tang, L. R. (2020). Effects of epidemic disease outbreaks on financial performance of restaurants: Event study method approach. Journal of Hospitality and Tourism Management, 43, 32-41. https://doi.org/10.1016/j. jhtm.2020.01.015

Lee, J. W., \& McKibbin, W. J. (2004). Globalization and disease: The case of SARS. Asian Economic Papers, 3(1), 113-131. https://doi.org/10.1162/1535351041747932

Lin, C. M., Lee, Y. H., \& Chiu, C. L. (2010). Friends or enemies? Foreign investors in Taiwan. Applied Economics Letters, 17(10), 977-982. https://doi.org/10.1080/17446540802599663

Liu, H. Y., Manzoor, A., Wang, C. Y., Zhang, L., \& Manzoor, Z. (2020). The COVID-19 outbreak and affected countries stock market response. International Journal of Environmental Research and Public Health, 17(8), 1-21. https://doi. org/10.3390/ijerph17082800

Lu, Y. C., Fang, H., \& Nieh, C. C. (2012). The price impact of foreign institutional herding on large-size stocks in the Taiwan stock market. Review of Quantitative Finance and Accounting, 39, 189-208. https://doi.org/10.1007/s11156011-0244-1

Malatesta, P. H. (1986). Measuring abnormal performance: The event parameter approach using joint generalized least squares. Journal of Financial and Quantitative Analysis, 21(1), 27-38. https://doi.org/10.2307/2330988

McKibbin, W., \& Fernando, R. (2020). The economic impact of COVID-19. In: R. Baldwin and B. W. di Mauro (Eds.), Economics in the Time of COVID-19 (pp. 45-51), London, UK: CEPR Press. https://cepr.org/sites/default/files/news/ COVID-19.pdf

Mehta, C. A. K., \& Jha, S. S. (2020). COVID-19: A nightmare for the Indian economy. UGC Care Journal, 31(20), 333-347. https://www.purakala.com/index.php/0971-2143/article/ view/1311

Onishchenkoa, O., \& Ulkub, N. (2019). Foreign investor trading behavior has evolved. Journal of Multinational Financial Management, 51, 98-115. https://doi.org/10.1016/j. mulfin.2019.04.005

Peterson, P. P. (1989) Event studies: A review of issues and methodology. Quarterly Journal of Business and Economics, 28(3), 36-66. Retrieved from https://www.jstor.org/ stable/40472954?seq=1

Polkuamdee, N., Chudasri, D., \& Sangwongwanich, P. (2020, February 20). SET worst-hit bourse in region. Bangkok Post. Retrieved April 10, 2020 from https://www.bangkokpost.com/ business/1864934/set-worst-hit-bourse-in-region

Ramelli, S., \& Wagner, A. F. (2020). Feverish stock price reactions to COVID-19. CEPR Discussion Paper No. DP14511. University of Zurich, Zurich, Switzerland. Retrieved from https://ssrn.com/abstract=3550274

Richards, A. (2005). Big fish in small ponds: The trading behavior and price impact of foreign investors in Asian emerging equity markets. Journal of Financial and Quantitative Analysis, 40(1), 1-27. https://doi.org/10.1017/S0022109000001721

Salinger, M. (1992). Standard errors in event studies. Journal of Financial and Quantitative Analysis, 27(1), 39-53. https://doi. org/10.2307/2331297

Schwarz, G. (1978). Estimating the dimension of a model. Annals of Statistics, 6(2), 461-464. https://doi.org/10.1214/ aos/1176344136

Sias, R. (2004). Institutional herding. Review of Financial Studies, 17(1), 165-206. https://doi.org/10.1093/rfs/hhg035

Stiglitz, J. E. (1998, March 25). Boats, planes and capital flows. Financial Times. Retrieved April 10, 2020 from: http://www. geocities.ws/mugajava.geo/riwa/gstigl.htm 
Takahashi, H., \& Yamada, K. (2020). When Japanese stock market meets COVID-19: Impact of ownership, China and US exposure, ESG, and liquidity channels. SSRN Paper. Available at SSRN: http://dx.doi.org/10.2139/ssrn.3577424

Thompson, R. (1985). Conditioning the return-generating process on firm-specific events: A discussion of event study methods. Journal of Financial and Quantitative Analysis, 20(2), 151-168. https://doi.org/10.2307/2330952

Vu, V. T. T., Phan N. T., \& Dang, H. N. (2020). Impacts of ownership structure on systemic risk of listed companies in Vietnam. Journal of Asian Finance, Economics and Business, 7(2), 107-117. https://doi.org/10.13106/jafeb.2020.vol7.no2.107

Wang, K. M., \& Tai, T. B. N. (2006). Does contagion effect exist between stock markets of Thailand and Chinese Economic Area (CEA) during the "Asian Flu?" Asian Journal of Management and Humanity Sciences, 1(1), 16-36.
World Federation of Exchanges. (2019). Statistics: Monthly Report. January 2020. Retrieved April 10, 2020 from: https:// focus.world-exchanges.org/issue/january-2020/marketstatistics

Worldometers. (2020, May 23). Reported cases and deaths by country, territory, or conveyance. Retrieved May 30, 2020 from: https:/www.worldometers.info/coronavirus/

Yaha, A., Singh, N., \& Rabanal, J. P. (2017). How do extreme global shocks affect foreign portfolio investment? An event study for India. Emerging Markets Finance and Trade, 53(8), 1923-1938. https://doi.org/10.1080/154049 6X.2016.1204599

Zivot, E., \& Wang, J. (2006). Modeling Financial Time Series with S-Plus ${ }^{\circledR}$ (2nd ed.). New York, NY: Springer. https://doi. org/10.1007/978-0-387-32348-0_11 